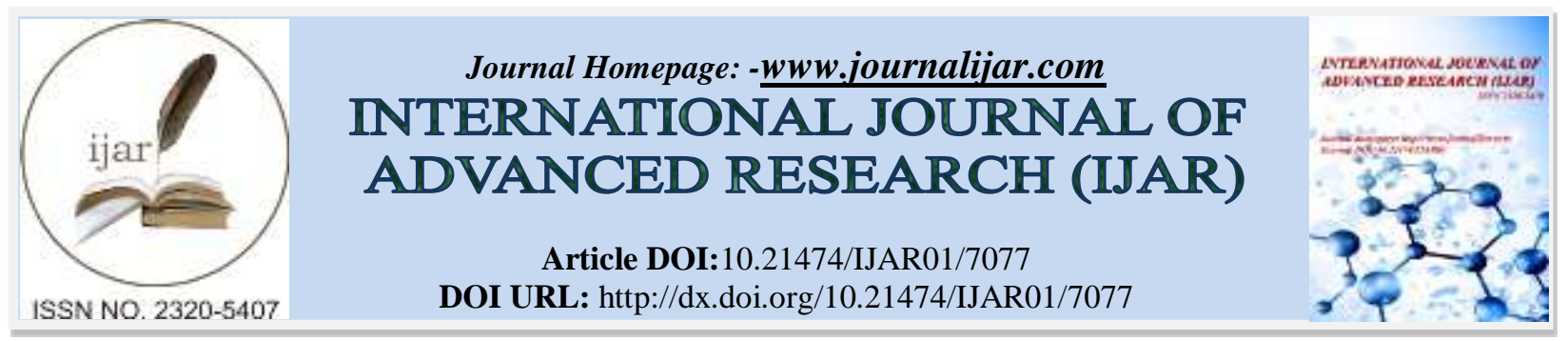

RESEARCH ARTICLE

\title{
IMPACT OF PERSONALITY FACTORS OF FACULTY ON ACADEMIC PERFORMANCE OF ENGINEERING STUDENTS.
}

Saranya. T. Jaikumar ${ }^{1}$ and Dr. T. Santhanam ${ }^{2}$.

1. Research Scholar of Shri JJT University, Jhunjhunu, Rajasthan, India.

2. Professor, SDS Institute Of Behavioral Sciences, Chennai, TamilNadu, India.

\section{Manuscript Info}

Manuscript History

Received: 11 March 2018

Final Accepted: 13 April 2018

Published: May 2018

Keywords: -

Engineering education, Personality

Factors, Engineering Faculty, Academic

Performance, Engineering students.

\begin{abstract}
Teachers and their approaches to teaching performance a very crucial function in creating the student an effective engineer in this very economical world. This research mainly focuses on how teaching engineering can be through efficiently by evaluating the personality arrangement of faculty as measured by MBTI. This novel line of investigation will make significant outcomes that are of applied inferences for teacher education and will observe numerous principle criteria of real teaching in terms of personality pattern features and their relationship with the academic presentation of the students taught by that faculty. Therefore, making improved faculty and enhanced engineers in upcoming is the main advantage for the culture from this exploration.
\end{abstract}

Copy Right, IJAR, 2018, All rights reserved.

\section{Introduction: - \\ Background: - \\ 1. Studying engineering carries the prestige \\ 2. It sets you up for proficient achievement \\ 3. It takes economic safety \\ 4. Gets you a chance to advance the world}

Bachelor of Engineering (B.E) is an Undergraduate Academic Degree granted for a course or program in the field of Engineering. In India, the period of Bachelor of Engineering Degree reserves over a period of 4 years. The 4 years course contains 8 semesters of education and a project in final year. Only students from the science stream (Biomath's and computer math's) at +2 levels (XI and XII) are qualified for the Bachelor of Engineering progression. Selection to BE is based on merit, which are the marks fortified in the concluding exams of $10+2$ and through entrance exams. Most generally students in India select to study engineering for the succeeding explanations.

The important goal for poor job predictions, rendering to the Ambitious Attentions' study's report, is “insufficient preparation in the domain area, the aptitude to smear basic values of say, computer engineering or mechanical engineering, to real-world problems. As many as $91.8 \%$ of computer/IT engineers and $60 \%$ of engineers from other divisions fall short of the sphere information essential for such characters. These thoughts and principles are there in college prospectus, however, there is a break in teaching and learning pedagogy being shadowed in the mainstream of colleges." So, the teachers and their approaches to teaching play a very crucial part in building the student an effective engineer in this very modest world. The main objective of this research focuses on how teaching engineering can be finished efficiently by studying the classroom behavior of engineering faculty. 
Teacher workforce is regarding naturally fewer operative than their more expert peers [1]. (Chingos \& Peterson, 2011). Relative to first-year teachers, for example, North Carolina basic grade teachers with 3 to 5 years of involvement add $9 \%$ and $6 \%$ of an SD to student attainment on end-of-grade examinations in mathematics and analysis [2]. (Clotfelter, Ladd, \& Vigdor, 2007). Then, novice teachers are expressively more perspective to exit the occupation. This erosion involves financial costs for districts and has opposing things on school constancy and student success [3,4]. (Alliance for Excellent Education, 2014; Ronfeldt, Loeb, \& Wyckoff, 2013). Lastly, novice teachers are unreasonably employed in high-need schools and classrooms, where students essential the highestquality possessions to improve their success [5,6]. (Bastian, Henry, \& Thompson, 2013; Clotfelter et al., 2005).

1. This study was designed based on a review from designated colleges in Chennai and so it is limited to this area and may not similar to those from other parts of India.

2. This investigation was lead based on analysis from engineering students and faculty and may not smear to those from other disciplines like medicine, arts, law, nursing, basic sciences, tourism, sports, commerce, graphics \& multimedia or business studies.

Recently, teacher education investigation has made important paces in reviewing the multifaceted relations between teacher views and performs. This new line of the examination will make significant results that are of applied implications for teacher education and will observe multiple criteria of real teaching in classrooms of specialized colleges.

1. The outcomes are valuable to select faculty during recruitment in engineering colleges as the study gives the connection between the classroom behavior and the performance of his / her students in the university exam for the subject handled by that faculty. Therefore leniency, teaching capacity, innovation and classroom control capacity of the faculty can all be taken into deliberation through faculty enrolment.

2. The outcomes are valuable for topic and classroom allotment during the opening of the semester.

3. Making well faculty and enhanced engineers in upcoming will be the main advantage for the society from this study.

\section{Personality: -}

Personality is well-defined as an individual's unique and comparatively reliable design of thoughtful, sensitivity and performing. Teachers have their own personal pattern. Personality is that which springs order and correspondence to all the diverse types of behavior in which the individual occupies. Recent research has prepared personality traits into universal factors that can be used to define a personality in a working atmosphere.

1. Big 5 personality factors that define the individual's alteration, sociability, conscientiousness, kindness and knowledgeable openness.

2. Self-esteem significances from an individual have sustained self-evaluation.

3. Locus of control refers to the extent to which individuals believe that they can control events affecting them.

4. Goal orientation

5. Introversion and extroversion.

Personality as is assessed by MBTI limited of the following sizes:

1. Extroversion: - They narrate more simply to the external world of persons and things.

2. Introversion: - They communicate more effortlessly to the inner world of thoughts.

3. Sensation: - They would contract with known evidence and don't aversion a recognized way of responsibility belongings.

4. Intuition: -They would somewhat look for potentials and relations that effort with known facts.

5. Thinking: - They base their decision more on objective examination and logic than on individual values.

6. Feeling: -They base their decision more on individual values than impersonal examination and reason.

7. Judging: They like a planned, decided, orderly way of life improved than a flexible, spontaneous way.

8. Perceptive: They like flexible, spontaneous way of life better than planned, orderly way.

Previous studies in psychology and economics highlight the position of personality characters and individual potentials [7] (Duckworth \& Yeager, 2015) to individuals' academic, workplace, and livelihood outcomes [8] (Ozer $\&$ Benet-Martinez, 2006). For example, actions of self-discipline, not IQ scores, more precisely expect middle school students' grade point averages [9](Duckworth \& Seligman, 2005). Likewise, actions of childhood selfcontrol expressively expect physical health, substance requirement, personal finances, and criminal effects for grown person [10] (Moffitt et al., 2011). Building on this body of work, promising research in education designates that teachers' behavior traits are pointedly connected with their presentation and retaining consequences [11, 12, 13]. (Klassen \& Tze, 2014; Robertson-Kraft \& Duckworth, 2014; Rockoff et al., 2011). Personality traits, matching 
with other features accessible at the appointment, may exist a way to expect additional of the difference in teacher presentation and permit the hiring of more operative and determined teachers [13]. (Rockoff et al., 2011). This is mainly applicable since personality traits are not simply dismissed with academic traits; relatively, they forecast unique foundations of variation in consequences of awareness [14]. (Lounsbury, Sundstrom, Loveland, \& Gibson, 2003).

\section{Objectives:-}

1. To study personality patterns of college faculty.

2. To study the association between staff personality and academic performance of students.

3. To propose the findings as methods to improve quality of engineering college faculty through Faculty Development Programme.

4. To propose the findings as methods to aide subject and classroom allotment to the staff at the beginning of the semester.

\section{Hypothesis:-}

Hypothesis 1: There is a significant relationship between faculty's MBTI personality factor Extrovert/Introvert and students' academic performance.

Hypothesis 2: There is a significant relationship between faculty's MBTI personality factor Sensing/Intuiting and students' academic performance.

Hypothesis 3: There is a significant relationship between faculty's MBTI personality factor Thinking/Feeling and students' academic performance.

Hypothesis 4: There is a significant relationship between faculty’s MBTI personality factor Judging/Perceiving and students' academic performance.

\section{Methods:- \\ Research Design:-}

It is an Assessment Study by Ex post facto design, where independent variables, existing in the participants (engineering faculty) prior to the research, affect a dependent variable. Here the independent variables are the personality factors of faculty as rated by MBTI and the dependent variable is the academic presentation of their students. As the independent variable in question is somewhat that is a distinctive characteristic of the faculty complicated Quasi-experiment is hired as the research focuses on independent variables that cannot be randomly dispensed.

\section{Sampling:-}

Population:- There are 552 engineering colleges in Tamil Nadu as of July 2016. Out of which 130 engineering colleges are in Chennai city. Every engineering college has an average of 50 teaching faculty. Thus there is nearly 6500 teaching faculty in engineering colleges in Chennai. Around 75000 students are studying in these colleges in numerous divisions of engineering. This study uses a grouping of random sampling and systematic sampling.

1. Sample 1 includes 200 engineering staff from several engineering colleges in Chennai who will take the MBTI test for personality testing. Here systematic sampling and random sampling is used. The 20 engineering colleges from Chennai are systematically designated based on their location in Chennai. Thus, from each college 10 faculties are then nominated by random sampling.

2. Sample 2 includes the same 200 engineering faculty who will be detected using an observatory schedule.

3. Sample 3 includes about 8000 students (those students who are taught by the above-mentioned faculty) whose academic presentation particulars are attained from college.

\section{Data Source and Data Collection:-}

\section{Primary Data Sources:-}

\section{Test of Personality Pattern Of Staff:-}

The responses established from staff by using Maier's Brick Personality Testing tool along with questions to collect personal data like age, gender, and position. The Myer Briggs Type Indicator was developed to assess the personality types. The revised and shortened version of MBTI consists of 50 items alternative either or expectations based on one's predilection, with pairs of assessment for each item. Scoring will then be complete as per the key. Thus, MBTI test will arrive at the teaching staff's main character includes the following variables

- $\quad$ Extroversion / Introversion

- $\quad$ Sensation / Intuition 
- $\quad$ Thinking / Feeling

- $\quad$ Judging / Perceptive

Validity: The validity of the test has been previously recognized by the author. Therefore, the present investigator not made any attempt to create the validity again.

Reliability: Test-retest reliability has been established by the researcher. The ' $r$ ' value is 0.72 which is highly significant at 0.01 level.

\section{Secondary Data Source:-}

1. Personal details of faculty:-

- $\quad$ Name of the faculty

- $\quad$ Age of the faculty

- $\quad$ Gender of the faculty (Male / Female)

- $\quad$ The position of the faculty (Lecturer / Assistant Professor / Associate Professor /

Professor)

- $\quad$ College the faculty is working for.

- $\quad$ The department that the faculty belongs to in the workplace.

- $\quad$ Each faculty id in assigned a unique faculty id number.

2. Academic Performance of the students: The University Exam results of the students are received from the college database. It gives the following details,

- University Exam results - Also referred as external exam results

$>\quad$ No: of Good performers

$>\quad$ No: of Average Performers

$>\quad$ No: of Poor Performers

U Grade with a score of $<50$ marks (Failures) is considered Poor Performers.

Data Cleaning and Analysis on Collected Data:-

In this research, descriptive and inferential statistics data analysis has been carried out. Because the research is dealing with various samples, it uses inferential statistical testing techniques including Distribution and Comparison of collected data and statistical association using Chi-square test. Chi-square test for independence of two variables is used to check whether the variables are independent of each other or not.

Findings:-

TABLE I: Association of personality factor (E/I) of the Faculty with the university exam performance

\begin{tabular}{|l|l|l|l|l|l|l|}
\hline $\begin{array}{l}\text { S. } \\
\text { No }\end{array}$ & $\begin{array}{l}\text { PERSONALITY } \\
\text { FACTOR }\end{array}$ & AVERAGE & GOOD & POOR & $\begin{array}{l}\chi^{2} \\
\text { VALUE }\end{array}$ & $\begin{array}{l}\text { LEVEL } \\
\text { SIGNIFICANCE }\end{array}$ \\
\cline { 1 - 4 } $\mathbf{1 .}$ & EXTROVERT (E) & $4302(54 \%)$ & $\begin{array}{l}1586 \\
(21 \%)\end{array}$ & $\begin{array}{l}2027 \\
(25 \%)\end{array}$ & 14.36. & Significant at 0.05 \\
\cline { 1 - 3 } & & & $\begin{array}{l}117 \\
(16 \%)\end{array}$ & $\begin{array}{l}148 \\
(23 \%)\end{array}$ & & \\
\hline
\end{tabular}

A chi-square test was performed to test the association between the academic performance of students in the university exam and the personality factor Extrovert / Introvert of MBTI personality pattern. The result of the chisquare statistic was found to be 14.3617 resulting in p-value 0.000761. As p-value is lesser than 0.05 and the association was found to be significant. Thus, there is an association between the academic performance of students in the university exam and the personality factor Extrovert / Introvert of MBTI personality pattern. This proves the alternate hypothesis. Thus, the null hypothesis is rejected.

TABLE II: Association of personality factor (S/N) of the Faculty with the university exam performance

\begin{tabular}{|c|c|c|c|c|c|c|}
\hline $\begin{array}{l}\text { S. } \\
\text { No }\end{array}$ & $\begin{array}{l}\text { PERSONALITY } \\
\text { FACTOR }\end{array}$ & AVERAGE & GOOD & POOR & $\chi^{2}$ VALUE & $\begin{array}{l}\text { LEVEL OF } \\
\text { SIGNIFICANCE }\end{array}$ \\
\hline 1. & SENSING (S) & $2699(55 \%)$ & $\begin{array}{l}968 \\
(20 \%)\end{array}$ & $\begin{array}{l}1202 \\
(25 \%)\end{array}$ & \multirow[t]{2}{*}{19.37} & \multirow[t]{2}{*}{ Significant at 0.05} \\
\hline 2. & INTUITING (N) & $2242(60 \%)$ & $\begin{array}{l}635 \\
(17 \%)\end{array}$ & $863(23 \%)$ & & \\
\hline
\end{tabular}


A chi-square test was performed to test the association between the academic performance of students in the university exam and the personality factor Sensing / Intuiting of MBTI personality pattern. The result of the chisquare statistic was found to be 19.3703 resulting in p-value 0.000062 . As p-value is lesser than 0.05 and the association was found to be significant. Thus, there is an association between the academic performance of students in the university exam and the personality factor Sensing / Intuiting of MBTI personality pattern. This proves the alternate hypothesis. Thus, the null hypothesis is rejected.

TABLE III:- Association of personality factor (T/F) of the Faculty with the university exam performance

\begin{tabular}{|c|c|c|c|c|c|c|}
\hline $\begin{array}{l}\text { S. } \\
\text { No }\end{array}$ & $\begin{array}{l}\text { PERSONALITY } \\
\text { FACTOR }\end{array}$ & AVERAGE & GOOD & POOR & $\chi^{2}$ VALUE & $\begin{array}{l}\text { LEVEL OF } \\
\text { SIGNIFICANCE }\end{array}$ \\
\hline 1. & Thinking (T) & $3111(56 \%)$ & $\begin{array}{l}1083 \\
(20 \%)\end{array}$ & $\begin{array}{l}1344 \\
(24 \%)\end{array}$ & \multirow[t]{2}{*}{11.83} & \multirow[t]{2}{*}{ Significant at 0.05} \\
\hline 2. & Feeling $(\mathrm{F})$ & $1830(60 \%)$ & $\begin{array}{l}520 \\
(17 \%)\end{array}$ & $\begin{array}{l}721 \\
(23 \%)\end{array}$ & & \\
\hline
\end{tabular}

A chi-square test was performed to test the association between the academic performance of students in the university exam and the personality factor Thinking / Feeling of MBTI personality pattern. The result of the chisquare statistic was found to be 11.8283 resulting in p-value 0.002701 . As p-value is lesser than 0.05 and the association was found to be significant. Thus, there is an association between the academic performance of students in the university exam and the personality factor Thinking / Feeling of MBTI personality pattern.

This proves the alternate hypothesis. Thus, the null hypothesis is rejected.

Table IV:- Association of personality factor (J/P) of the Faculty with the university exam performance

\begin{tabular}{|l|l|l|l|l|l|l|}
\hline $\begin{array}{l}\text { S. } \\
\text { No }\end{array}$ & $\begin{array}{l}\text { PERSONALITY } \\
\text { FACTOR }\end{array}$ & AVERAGE & GOOD & POOR & $\chi^{2}$ VALUE & $\begin{array}{l}\text { LEVEL } \\
\text { SIGNIFICANCE }\end{array}$ \\
\cline { 1 - 4 } $\mathbf{1 .}$ & Judging (J) & $2315(58 \%)$ & $721(18 \%)$ & $\begin{array}{l}972 \\
(24 \%)\end{array}$ & 7.14 & Significant at 0.05 \\
\cline { 1 - 3 } & Perceiving (P) & $2576(56 \%)$ & $932(21 \%)$ & $\begin{array}{l}1093 \\
(23 \%)\end{array}$ & & \\
\hline
\end{tabular}

A chi-square test was achieved to test the association between the academic performance of students in the university exam and the personality factor Judging / Perceiving of MBTI personality pattern. The result of the chisquare statistic was found to be 7.1386 resulting in p-value 0.028176. As p-value is lesser than 0.05 and the association was found to be significant. Thus, there is an association between the academic performance of students in the university exam and the personality factor Judging / Perceiving of MBTI personality pattern. This proves the alternate hypothesis. Thus, the null hypothesis is rejected.

\section{Discussion:-}

Thus taking both pass percentage and number of high scorers in class into consideration, students taught by perceiving staff always performed well comparatively.

Staffs

- who relate more easily to the outer world of people and things

- who would deal with known facts and don't dislike an established way of doing things

- who would make their judgment more on logic than on personal values

- who are flexible, spontaneous way of life better than planned, orderly way

Were found to have the capacity to produce a number of high scorers in class but the overall pass percentage was low when compared to staff with other personality patterns. So ESTP personality staff are found to be most efficient with good scorers but cannot teach the below average students effectively.

On the other hand, staffs

- Who can relate more easily to the inner world of ideas?

- Who would rather look for possibilities and relationships that work with known facts

- Who base their judgment more on personal values than impersonal analysis and logic 
- Who like flexible, spontaneous way of life better than planned, orderly way, Were found to have the capacity to produce a good pass percentage in his/her class but the number of high performers was low when compared to staff with other personality patterns. So INFP personality staffs are found to be most efficient with average and below average students but are not very effective with the good scorers.

Students of engineering faculty who like a planned, decided, arranged way of life improved than a flexible, unprompted way were found to have a low academic presentation. The current research is in line with the study made by Kevin C. Bastian [15] who made a study on A Temperament for Teaching? According to the authors who studied Associations between Personality Traits and Beginning Teacher Performance and Retention, there is a rich body of suggestion linking conscientiousness-related measures to employee presentation and retaining across professions, and they recommend that regions and schools should deliberate using personality trait procedures, along with other valid displays, as a way to recover teacher-hiring choices. The existing research is in similar with the study of Ajeya Jha [16], who conducted a study to recognize the association between EI and teaching performance in the case of faculty members at medical and engineering colleges, as courses connected to these two fields are fairly wide and challenging which often leads to stress among students. This study is similarly correlated with the additional study "The impact of teacher personality styles on the academic excellence of secondary students" made by Patricia Lee Stout Garcia[17].

\section{Conclusions:-}

In this investigation, it is established that there is a significant connection between faculty's MBTI personality factor Extrovert/Introvert and students' academic performance. Thus, a class trained by staff with introvert personality factor show improved passes percentage in their university examinations but extrovert staff produces a number of good performers. This research also demonstrated that there is a significant relationship between faculty's MBTI personality factor Sensing/Intuiting and students' academic performance and so a class taught by staff with perceiving personality factor have better pass percentage in their university exams but a sensing staff produces more high scorers. Also, it is found that there is a significant relationship between faculty's MBTI personality factor Thinking/Feeling and students' academic performance and so a class taught by staff with feeling personality factor have better pass percentage in their university exams but a thinking staff produces more high scorers. It is also showed in this study that there is a significant relationship among faculty's MBTI personality factor Judging/Perceiving and students' academic performance and so students taught by staff with perceiving personality factor show improved academic performance in their university exams in terms of a number of high scorers and in terms of pass percentage. Hence it is showed through this research that subjects taught by staff in engineering colleges with personality type INFP had enhanced pass percentage than staff with ESTJ personality. Further, it is showed through this study that subjects taught by staff in engineering colleges with personality type ESTP had a number of good performers than staff with INFJ personality pattern although the pass percentage was low. The author was motivated on responsible the relationship between teacher personality styles and academic performance of $10^{\text {th }}$ and $11^{\text {th }}$-grade students and according to the author, the results showed a significant impact of the personality of a teacher on students in school.

\section{References:-}

1. Chingos MM, Peterson PE (2011) It's easier to pick a good teacher than to train one: Familiar and new results on the correlates of teacher effectiveness. Economics of Education Review, 30(3), 449-465.

2. Clotfelter CT, Ladd HF, Vigdor JL (2007) Teacher credentials and student achievement: Longitudinal analysis with student fixed effects. Economics of Education Review, 26(6), 673-682.

3. Alliance for Excellent Education (2014) On the path to equity: Improving the effectiveness of beginning teachers.

4. Ronfeldt M, Loeb S, Wyckoff J (2013) How teacher turnover harms student achievement. American Educational Research Journal, 50(1), 4-36.

5. Bastian KC, Henry GT, Thompson CL (2013) Incorporating access to more effective teachers into assessments of educational resource equity. Education Finance and Policy, 8(4), 560-580.

6. Clotfelter CT, Ladd HF, Vigdor JL (2005) Who teaches whom? Race and the distribution of novice teachers. Economics of Education Review, 24(4), 377-392

7. Duckworth AL, Yeager, DS (2015) Measurement matters: Assessing personal qualities other than cognitive ability for educational purposes. Educational Researcher, 44(4), 237-251. 
8. Ozer D J, Benet-Martinez V (2006) Personality and the prediction of consequential outcomes. Annual Review of Psychology, 57, 401-421.

9. Duckworth AL, Seligman ME (2005) Self-discipline outdoes IQ in predicting academic performance of adolescents. Psychological Science, 16(12), 939-944.

10. Moffitt TE, Arseneault L, Belsky, Dickson N, Hancox RJ, Harrington H, Caspi A (2011) A gradient of childhood self-control predicts health, wealth, and public safety. Proceedings of the National Academy of Sciences of the United States of America, 108(7), 2693-2698.

11. Klassen RM, Tze V (2014) Teachers' self-efficacy, personality, and teaching effectiveness: A meta-analysis. Educational Research Review, 12, 59-76.

12. Robertson-Kraft C, Duckworth AL (2014) True grit: Traitlevel perseverance and passion for long-term goals predicts effectiveness and retention among novice teachers. Teachers College Record, 116(3), 1-27.

13. Rockoff JE, Jacob BA, Kane TJ, Stagier DO (2011) Can you recognize an effective teacher when you recruit one? Education Finance and Policy, 6(1), 43-74.

14. Lounsbury J W, Sundstrom E, Loveland JM, Gibson LW (2003) Intelligence, "Big Five" personality traits, and work drive as predictors of course grade. Personality and Individual Differences, 35(6), 1231-1239.

15. Bastian KC, McCord DM, Marks JT, Carpenter D (2017) A temperament for teaching? Associations between personality traits and beginning teacher performance and retention. AERA Open, 3(1), 2332858416684764.

16. Singh I, Jha A (2012) Teacher effectiveness in relation to emotional intelligence among medical and engineering faculty members. Europe's Journal of Psychology, 8(4), 667-685.

17. Garcia PLS (2010) The impact of teacher personality styles on academic excellence of secondary students. Texas A\&M University-Kingsville. 